\title{
Modulation of inflammatory signaling pathways by phytochemicals in ovarian cancer
}

\author{
Mi-Kyung Kim • Kidong Kim • Jae Yong Han • \\ Jeong Mook Lim $\cdot$ Yong Sang Song
}

Received: 8 October 2010/ Accepted: 4 January 2011/Published online: 4 February 2011

(C) Springer-Verlag 2011

\begin{abstract}
Inflammation has been suggested to be involved in cancer development and progression. Many clinical and experimental studies have shown that inflammation could contribute to ovarian carcinogenesis through activation of the NF- $\kappa \mathrm{B}$ and AP-1 pathways by chronic inflammatory mediators. Phytochemicals, which are natural compounds derived from fruits and vegetables, have shown anti-inflammatory and anti-cancer effects. Due to their relatively low toxicity and easy accessibility, phytochemicals have been investigated for their chemopreventive potential against various cancers. In this review, we discuss the role of phytochemicals in preventing ovarian cancer through anti-inflammatory mechanisms.
\end{abstract}

Keywords Phytochemicals - Ovarian cancer .

Anti-inflammation · Chemoprevention

M.-K. Kim and K. Kim contributed equally to this work.

M.-K. Kim · Y. S. Song ( $₫)$

Department of Obstetrics and Gynecology, Seoul National

University College of Medicine, 28 Yongon-Dong,

Chongno-Gu, Seoul 110-744, Republic of Korea

e-mail: yssong@snu.ac.kr

\section{K. Kim}

Department of Obstetrics and Gynecology, Korea Cancer Center Hospital, Korea Institute of Radiological and Medical Sciences, Seoul, Republic of Korea

J. Y. Han · J. M. Lim · Y. S. Song

Major in Biomodulation, WCU and Department of Agricultural

Biotechnology, Seoul National University,

Seoul, Republic of Korea

Y. S. Song

Cancer Research Institute, Seoul National University College

of Medicine, Seoul, Republic of Korea

\section{Introduction}

Ovarian cancer is the fifth leading cause of cancer deaths in women and is the most lethal gynecologic malignancy [27]. The poor prognosis of ovarian cancer results mainly from the high percentage of cases diagnosed at an advanced stage. Although most patients with advanced ovarian cancer respond to first-line chemotherapy, $80 \%$ of patients will ultimately succumb to death due to recurrence.

Chemoprevention refers to the use of natural or synthetic agents to inhibit, delay, or reverse the development of cancer. There have been numerous in vitro and animal studies evaluating the efficacy of chemopreventive agents, including natural compounds, hormones, or other targeted agents, in various cancer models. Phytochemicals, which are natural compounds derived from fruits and vegetables, have been extensively investigated for their anti-cancer activities due to their safety, low toxicity, and general availability [5]. The major dietary sources of phytochemicals include garlic, soybeans, ginger, grapes, green tea, turmeric, and cruciferous vegetables [62]. These natural compounds have been reported to target multiple signaling pathways involved in carcinogenesis, such as cell proliferation, apoptosis, angiogenesis, and inflammatory signaling pathways. Given the complexity of crosstalk between cell signaling pathways in individual cancers, phytochemicals that affect diverse pathways have the advantage in chemoprevention over targeted agents, which inhibit single pathways and, therefore, have shown only modest inhibitory effects on tumor growth.

In ovarian cancer, chemoprevention is also gaining interest due to the limitations of current therapeutic modalities in improving survival outcomes, as well as the lack of efficient screening strategies. In this review, we will discuss the role of phytochemicals in the chemoprevention 
Fig. 1 Two-pathway model of ovarian carcinogenesis. Highgrade tumors grow rapidly without identifiable precursor lesions, and more frequently harbor P53 mutations. In contrast, low-grade tumors grow more slowly and share molecular characteristics with low-malignant potential ( $L M P$ ) tumors, such as $K$-Ras, $B R A F$, and PTEN mutations.

Additional alterations, including angiogenesis and achievement of potential for invasion and metastasis, are required for tumor progression to invasive ovarian cancers in both pathways

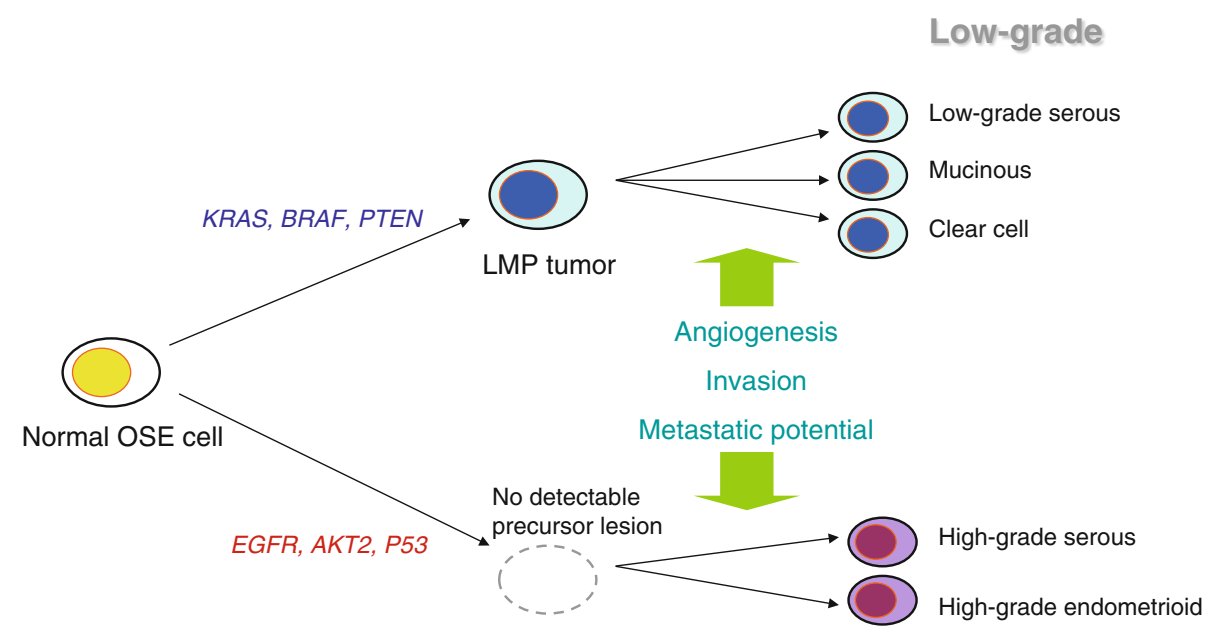

High-grade of ovarian cancer, especially in the context of their antiinflammatory functions.

\section{Ovarian carcinogenesis and inflammation}

\section{Ovarian carcinogenesis}

More than $90 \%$ of ovarian cancers are epithelial in origin and are thought to arise from ovarian surface epithelium or inclusion cysts. Multiple genetic alterations are implicated in ovarian carcinogenesis, but there are multiple lines of clinical and genetic evidence to support two broad categories of ovarian carcinogenesis (Fig. 1), those of lowgrade and high-grade pathways [33]. K-Ras, BRAF, and $P T E N$ mutations are more frequently observed in lowgrade tumors, whereas P53 mutation is predominantly present in high-grade tumors.

There have been several hypotheses about the underlying mechanisms of ovarian carcinogenesis. The first to arise was the ovulation hypothesis, which relates ovarian cancer risk to incessant ovulation [17]. To support this hypothesis, there has been substantial epidemiologic evidence demonstrating that oral contraceptive use or multiple pregnancies can decrease cancer risk. Other stimulating factors, such as gonadotropin or hormones, have also been suggested to increase the risk of ovarian cancer $[53,66]$. Recently, however, another compelling hypothesis has highlighted the role of inflammation in the development of ovarian cancer [42].

Inflammation in ovarian cancer

Inflammation has been suggested to contribute to every step of carcinogenesis, including tumor initiation, promotion, and progression [21]. Components of the inflammatory pathway, including free radicals, cytokines, NF- $\kappa \mathrm{B}$, signal transducer and activator of transcription-3 (STAT-3), inducible nitric oxide synthase (iNOS), cyclooxygenase-2 (COX-2), prostaglandins, and vascular endothelial growth factor (VEGF), have been shown to contribute to the development of various malignancies, including ovarian cancer. In ovarian cancer samples, COX-2 was found to be highly expressed in nonmucinous ovarian cancers, and the expression of COX-2 was correlated with poor prognostic factors, such as stage, residual disease status, and presence of ascites [54].

The ovulation process itself is believed to be associated with inflammatory pathways. Ovarian surface epithelium adjacent to the site of ovulation may be exposed to inflammatory cytokines and prostaglandins and may undergo active replication, thereby enhancing the risk of malignant transformation. In addition, there is epidemiologic evidence supporting the role of inflammation in ovarian carcinogenesis [42]. Some risk factors, including talc/asbestos exposure, endometriosis, and pelvic inflammatory disease, are known to enhance local inflammation, but not directly affect ovulation and hormone levels. Moreover, several studies have shown the inverse relationship between long-term nonsteroidal anti-inflammatory drug (NSAID) use and ovarian cancer risk [14, 52]. The proposed molecular targets of NSAIDs include NF- $\kappa \mathrm{B}$, iNOS, COX-2, and VEGF [4].

\section{Phytochemicals targeting inflammatory signaling pathways}

Based on the accumulating data supporting the role of inflammation in cancer development, clinical trials on 


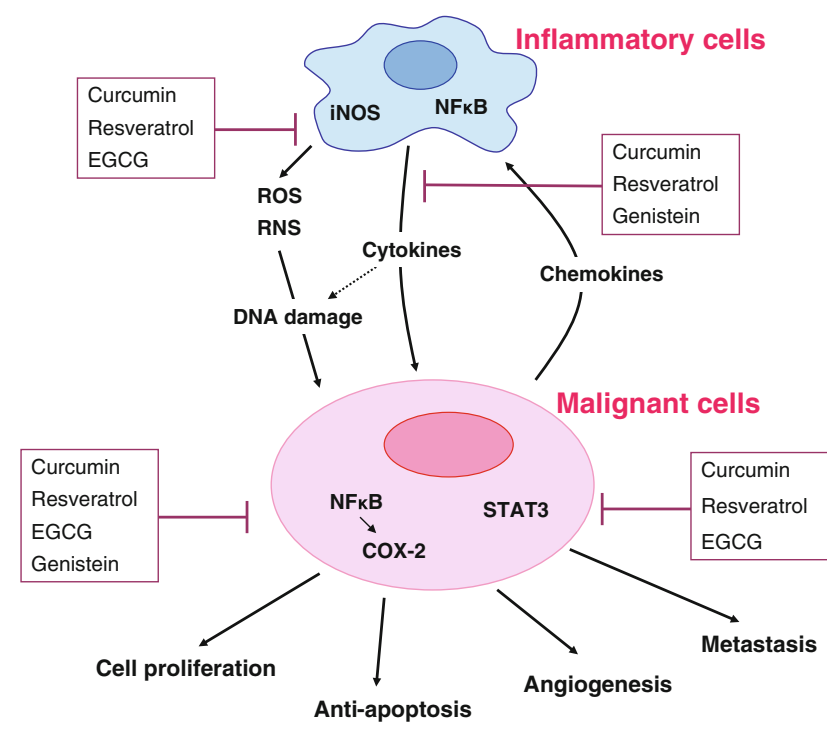

Fig. 2 A schematic diagram of inflammatory pathways involved in ovarian carcinogenesis and their inhibition by phytochemicals. Reactive oxygen species (ROS) and reactive nitrogen species (RNS) produced by inflammatory cells cause DNA damage to neighboring cells (tumor initiation). Activation of nuclear factor- $\kappa \mathrm{B}$ $(\mathrm{NF}-\kappa \mathrm{B})$ in inflammatory cells leads to the production of inflammatory cytokines, which activate transcription factors, such as NF- $\kappa \mathrm{B}$ and STAT-3, in initiated cells to promote cell proliferation, antiapoptosis, angiogenesis, and metastasis (tumor promotion and progression). Phytochemicals block each step of ovarian carcinogenesis through down-regulation of iNOS and COX-2 expression, inhibition of inflammatory cytokines, and the suppression of pleiotropic transcription factors NF- $\kappa \mathrm{B}$ and STAT-3

chemoprevention of various malignancies utilizing NSAIDs or COX-2 inhibitors have been conducted [28], and celecoxib, a selective COX-2 inhibitor, has been shown to be effective in reducing the occurrence of colorectal adenomas [6]. Despite their anti-cancer potential, however, clinical trials using COX-2 inhibitors, such as celecoxib and rofecoxib, were closed early due to the significantly increased risk of serious cardiovascular events $[39,60]$. As a result, researchers have turned their interest to phytochemicals, with their more acceptable safety profiles, and have started to investigate their chemopreventive activities.

Phytochemicals exert anti-cancer effects through the modulation of multiple signaling pathways, one of which is the inflammatory signaling pathway. Anti-inflammatory mechanisms associated with the anti-cancer effects of phytochemicals include suppression of NF- $\kappa \mathrm{B}$ activation, inhibition of STAT-3 activation, and down-regulation of COX-2, iNOS, or inflammatory cytokines (Fig. 2).

\section{Curcumin}

Curcumin, a component of turmeric, has traditionally been used as an anti-inflammatory drug. In addition to suppressing inflammation, recent studies have demonstrated that curcumin exhibits diverse activities, including antioxidant, anti-proliferative, and antiangiogenic activities, through interaction with multiple signaling pathways [32, 50]. The molecular targets of curcumin include transcription factors, growth factors, cytokines, enzymes, and other gene products [19].

$\mathrm{NF}-\kappa \mathrm{B}$ is a transcription factor and plays a key role in inflammation and cancer development by inducing several genes associated with anti-apoptosis, cell proliferation, angiogenesis, and metastasis [26]. Curcumin has been shown to inhibit NF- $\kappa \mathrm{B}$ activation induced by tumor necrosis factor (TNF), phorbol ester, hydrogen peroxide, or interleukin (IL)-1 in several cell lines [29, 57]. The inhibitory effect of curcumin on NF- $\kappa \mathrm{B}$ activation is believed to be due to the inhibition of I- $\kappa \mathrm{B}$ kinase (IKK) activity [29, 47, 58]. In multiple myeloma and melanoma cells, curcumin down-regulated NF- $\kappa \mathrm{B}$ and prevented nuclear translocation of p65 through the suppression of IKK activity [7, 46]. Down-regulated NF- $\kappa \mathrm{B}$, in turn, leads to decreased expression of inflammatory enzymes, such as COX-2 and iNOS [10, 47, 55, 67].

Likewise, curcumin has been shown to inhibit NF- $\kappa \mathrm{B}$ activation in ovarian cancer cells $[30,36]$. In several ovarian cancer cell lines (SKOV3ip1 and HeyA8), curcumin suppressed NF- $\kappa$ B and STAT-3 activation and inhibited expression of COX-2 [36]. EF24, a synthetic analog of curcumin, blocked the nuclear translocation of NF- $\kappa \mathrm{B}$ and inhibited TNF- $\alpha$-induced I- $\kappa \mathrm{B}$ degradation through direct inhibition of IKK activity [30]. Since NF- $\kappa$ B is also a transcription factor for inflammatory cytokines, curcumin has been demonstrated to attenuate the expression of IL-1, IL-6, and TNF- $\alpha$ [11]. Curcumin increased the sensitivity of SKOV3 and CAOV3 cells to cisplatin, and one of the suggested mechanisms was reducing the production of IL-6 [9]. In addition to inhibition of inflammatory cytokines, curcumin has also been shown to suppress angiogenic factors, such as VEGF, and subsequently inhibits angiogenesis in both in vitro and in vivo studies $[36,63]$.

In addition, there have been several animal studies demonstrating the anti-cancer effects of curcumin in skin, breast, and colon cancer models, mainly through antiinflammatory effects $[3,13,31,48]$. In a breast cancer model, dietary administration of curcumin to nude mice significantly reduced the incidence of lung metastasis, possibly through the inhibition of paclitaxel-induced expression of NF- $\kappa \mathrm{B}, \mathrm{COX}-2$, and MMP9 [3]. Similarly, in patients with pancreatic cancer, curcumin down-regulated the expression of $\mathrm{NF}-\kappa \mathrm{B}, \mathrm{COX}-2$, and phosphorylated STAT-3 in peripheral blood mononuclear cells [15]. In an orthotopic murine model of ovarian cancer, curcumin demonstrated inhibitory effects on tumor growth and angiogenesis [36]. In this study, treatment with curcumin alone or in combination with docetaxel significantly 
reduced the proliferation and microvessel density and increased tumor cell apoptosis in multidrug-resistant ovarian cancer tumors.

\section{Resveratrol}

Resveratrol, a phytoalexin abundantly found in grape skins and red wine, has been shown to have anti-inflammatory and anti-carcinogenic properties [62]. Resveratrol inhibits proliferation and induces apoptosis in various cancer cell lines, including breast, prostate, colon, and ovarian cancer cells [2]. In nude mice implanted with human ovarian cancer cells, resveratrol suppressed tumor growth when it was administered intraperitoneally, and apoptotic features were observed in the tumor tissues [22, 34]. Resveratrol also enhanced the efficacy of cisplatin and doxorubicin in ovarian cancer cells, while reducing the doxorubicin-related cardiac toxicity [51].

The inhibitory effects of resveratrol on tumor growth have been, in part, attributed to its anti-inflammatory activity [2]. In murine and human macrophage cells, resveratrol down-regulates NF- $\kappa \mathrm{B}$ activity in a dose-dependent manner, which coincides with suppression of AP-1 $[24,38,65]$. Similar to curcumin, inhibition of NF- $\kappa \mathrm{B}$ activity by resveratrol is considered to be mediated by blocking IKK activity [38]. Resveratrol also suppresses expression of inflammatory enzymes, such as iNOS and COX-2, in macrophages and various cancer cells through the inhibition of NF- $\kappa \mathrm{B}$ activity [35, 40, 61]. In ovarian cancer cells, resveratrol inhibits the expression of both basal level and growth factor-induced hypoxia-inducible factor- $1 \alpha($ HIF- $1 \alpha)$ [8, 45]. The underlying mechanism appears to be associated with the inactivation of mitogenactivated protein kinase (MAPK) and protein translational regulator p70S6K, as well as enhanced degradation of HIF- $1 \alpha$ protein through the proteasome pathway. Resveratrol also significantly suppresses vascular endothelial growth factor (VEGF) expression through inhibition of HIF- $1 \alpha$.

Taken together, these data suggest that resveratrol may inhibit ovarian carcinogenesis by down-regulating NF- $\kappa \mathrm{B}$ activity and suppressing HIF- $1 \alpha$ and VEGF expression.

\section{Genistein}

Genistein is a soy-derived isoflavone and has shown protective effects against endocrine-related gynecological cancers [41, 68]. A meta-analysis study demonstrated an inverse correlation between soy intake and ovarian cancer risk.

Genistein has been shown to inhibit cell proliferation, cause cell cycle arrest at $\mathrm{G} 2 / \mathrm{M}$ phase, and induce apoptosis in ovarian cancer cells [12, 44]. In addition, genistein treatment also induces autophagic cell death in ovarian cancer cells, which may contribute to its potential to overcome chemoresistance developed from an altered apoptotic signaling pathway [20]. In both platinum-sensitive and platinum-resistant ovarian cancer cells, genistein abrogated NF- $\kappa$ B DNA binding activity and down-regulated anti-apoptotic genes [59]. In addition, genistein suppressed VEGF expression in OVCAR-3 cells [37]. Among six flavonoids, genistein exhibited the most potent inhibitory effect on VEGF expression. Phenoxodiol, a synthetic analog of genistein, also demonstrated a potent inhibitory effect on in vivo angiogenesis [18]. Furthermore, soy isoflavones interfere with production of IL-6, which affects immune homeostasis and inflammatory reactions [16]. Aberrant IL-6 expression has been associated with various pathologic inflammatory conditions, tumor progression, and chemoresistance. Collectively, by modulating inflammatory signaling components including NF- $\kappa \mathrm{B}$, VEGF, and IL-6, genistein may be used as a chemopreventive agent in future clinical trials.

\section{EGCG}

Epigallocatechin-3-gallate (EGCG), a polyphenol constituent of green tea, has shown anti-proliferative and proapoptotic effects on several cancer cells, including melanoma, breast cancer, and prostate cancer [43, 64]. The underlying mechanisms include cell cycle arrest, apoptosis induction, stabilization of $\mathrm{p} 53$, and inhibition of NF- $\kappa \mathrm{B}$ activity $[1,23,43,64]$. There are limited data on its anticancer effects in ovarian cancer cells. EGCG treatment in SKOV-3 cells resulted in inhibition of cell viability and proliferation via induction of apoptosis [49]. In several ovarian cancer cell lines, EGCG exerted its inhibitory effect on cancer cell growth through the induction of apoptosis and cell cycle arrest as well as the regulation of cell cycle-related proteins [25]. The anti-inflammatory effects of EGCG in ovarian cancer need further investigation.

\section{Conclusion}

Inflammation has been hypothesized to contribute to ovarian carcinogenesis, and modulation of dysregulated inflammatory pathways has been investigated as a promising chemopreventive strategy against ovarian cancer. In numerous preclinical and clinical studies, phytochemicals have demonstrated anti-cancer effects, largely mediated by regulation of inflammatory pathways. Phytochemicals seem to be suitable candidates for further clinical trials on chemoprevention of various malignancies due to their safety profiles, easy accessibility, and the ability to target 
multiple signaling pathways involved in carcinogenesis, such as cell proliferation, apoptosis, angiogenesis, and inflammatory signaling pathways. However, there still remain several challenges to researchers, which include the low potency and poor bioavailability of phytochemicals. Curcumin, for example, was detected at low nanomolar levels in the blood of patients who received up to $3.6 \mathrm{~g}$ of oral curcumin [56]. Synthetic analogs of natural compounds, such as EF24 for curcumin, may increase their anti-tumor potency and improve bioavailability. In addition, more preclinical and clinical studies are needed to validate the chemopreventive effects of phytochemicals alone or in combination with conventional therapies against ovarian cancer.

Acknowledgments This work was supported by the Mid-career Researcher Program through the National Research Foundation of Korea (NRF) grant funded by the Ministry of Education, Science, and Technology (MEST; No. 2009-0083687) and Priority Research Centers Program through the NRF funded by the MEST (No. 2009-0093820). This research was also supported by the World Class University (WCU) program through the Korea Science and Engineering Foundation, funded by the MEST (R31-2008-000-10056-0).

\section{References}

1. Adhami VM, Malik A, Zaman N, Sarfaraz S, Siddiqui IA, Syed DN, Afaq F, Pasha FS, Saleem M, Mukhtar H (2007) Combined inhibitory effects of green tea polyphenols and selective cyclooxygenase- 2 inhibitors on the growth of human prostate cancer cells both in vitro and in vivo. Clin Cancer Res 13(5):1611-1619

2. Aggarwal BB, Bhardwaj A, Aggarwal RS, Seeram NP, Shishodia S, Takada Y (2004) Role of resveratrol in prevention and therapy of cancer: Preclinical and clinical studies. Anticancer Res 24(5A):2783-2840

3. Aggarwal BB, Shishodia S, Takada Y, Banerjee S, Newman RA, Bueso-Ramos CE, Price JE (2005) Curcumin suppresses the paclitaxel-induced nuclear factor-kappab pathway in breast cancer cells and inhibits lung metastasis of human breast cancer in nude mice. Clin Cancer Res 11(20):7490-7498

4. Altinoz MA, Korkmaz R (2004) Nf-kappab, macrophage migration inhibitory factor and cyclooxygenase-inhibitions as likely mechanisms behind the acetaminophen- and nsaid-prevention of the ovarian cancer. Neoplasma 51(4):239-247

5. Amin AR, Kucuk O, Khuri FR, Shin DM (2009) Perspectives for cancer prevention with natural compounds. J Clin Oncol 27(16):2712-2725

6. Arber N, Eagle CJ, Spicak J, Racz I, Dite P, Hajer J, Zavoral M, Lechuga MJ, Gerletti P, Tang J, Rosenstein RB, Macdonald K, Bhadra P, Fowler R, Wittes J, Zauber AG, Solomon SD, Levin B (2006) Celecoxib for the prevention of colorectal adenomatous polyps. New Engl J Med 355(9):885-895

7. Bharti AC, Donato N, Singh S, Aggarwal BB (2003) Curcumin (diferuloylmethane) down-regulates the constitutive activation of nuclear factor-kappa $\mathrm{b}$ and ikappabalpha kinase in human multiple myeloma cells, leading to suppression of proliferation and induction of apoptosis. Blood 101(3):1053-1062

8. Cao Z, Fang J, Xia C, Shi X, Jiang BH (2004) Trans-3, 4, 5'trihydroxystibene inhibits hypoxia-inducible factor 1alpha and vascular endothelial growth factor expression in human ovarian cancer cells. Clin Cancer Res 10(15):5253-5263
9. Chan MM, Fong D, Soprano KJ, Holmes WF, Heverling H (2003) Inhibition of growth and sensitization to cisplatin-mediated killing of ovarian cancer cells by polyphenolic chemopreventive agents. J Cell Physiol 194(1):63-70

10. Chan MM, Huang HI, Fenton MR, Fong D (1998) In vivo inhibition of nitric oxide synthase gene expression by curcumin, a cancer preventive natural product with anti-inflammatory properties. Biochem Pharmacol 55(12):1955-1962

11. Cho JW, Lee KS, Kim CW (2007) Curcumin attenuates the expression of il-1beta, il-6, and tnf-alpha as well as cyclin e in tnf-alpha-treated hacat cells; nf-kappab and mapks as potential upstream targets. Int J Mol Med 19(3):469-474

12. Choi EJ, Kim T, Lee MS (2007) Pro-apoptotic effect and cytotoxicity of genistein and genistin in human ovarian cancer sk-ov-3 cells. Life sci 80(15):1403-1408

13. Conney AH, Lysz T, Ferraro T, Abidi TF, Manchand PS, Laskin JD, Huang MT (1991) Inhibitory effect of curcumin and some related dietary compounds on tumor promotion and arachidonic acid metabolism in mouse skin. Adv Enzym Regulat 31:385-396

14. Cramer DW, Harlow BL, Titus-Ernstoff L, Bohlke K, Welch WR, Greenberg ER (1998) Over-the-counter analgesics and risk of ovarian cancer. Lancet 351(9096): 104-107

15. Dhillon N, Aggarwal BB, Newman RA, Wolff RA, Kunnumakkara AB, Abbruzzese JL, Ng CS, Badmaev V, Kurzrock R (2008) Phase ii trial of curcumin in patients with advanced pancreatic cancer. Clin Cancer Res 14(14):4491-4499

16. Dijsselbloem N, Vanden Berghe W, De Naeyer A, Haegeman G (2004) Soy isoflavone phyto-pharmaceuticals in interleukin-6 affections. Multi-purpose nutraceuticals at the crossroad of hormone replacement, anti-cancer and anti-inflammatory therapy. Biochem Pharmacol 68(6):1171-1185

17. Fathalla MF (1971) Incessant ovulation-a factor in ovarian neoplasia? Lancet 2(7716): 163

18. Gamble JR, Xia P, Hahn CN, Drew JJ, Drogemuller CJ, Brown D, Vadas MA (2006) Phenoxodiol, an experimental anticancer drug, shows potent antiangiogenic properties in addition to its antitumour effects. Int J Cancer 118(10):2412-2420

19. Goel A, Kunnumakkara AB, Aggarwal BB (2008) Curcumin as "Curecumin": from kitchen to clinic. Biochem Pharmacol 75(4):787-809

20. Gossner G, Choi M, Tan L, Fogoros S, Griffith KA, Kuenker M, Liu JR (2007) Genistein-induced apoptosis and autophagocytosis in ovarian cancer cells. Gynecol Oncol 105(1):23-30

21. Grivennikov SI, Greten FR, Karin M (2010) Immunity, inflammation, and cancer. Cell 140(6):883-899

22. Guo L, Peng Y, Yao J, Sui L, Gu A, Wang J (2010) Anticancer activity and molecular mechanism of resveratrol-bovine serum albumin nanoparticles on subcutaneously implanted human primary ovarian carcinoma cells in nude mice. Cancer Biother Radiopharmaceut 25(4):471-477

23. Hastak K, Gupta S, Ahmad N, Agarwal MK, Agarwal ML, Mukhtar H (2003) Role of p53 and nf-kappab in epigallocatechin3-gallate-induced apoptosis of lncap cells. Oncogene 22(31):4851-4859

24. Holmes-McNary M, Baldwin AS Jr (2000) Chemopreventive properties of trans-resveratrol are associated with inhibition of activation of the ikappab kinase. Cancer Res 60(13):3477-3483

25. Huh SW, Bae SM, Kim YW, Lee JM, Namkoong SE, Lee IP, Kim SH, Kim CK, Ahn WS (2004) Anticancer effects of (-)-epigallocatechin-3-gallate on ovarian carcinoma cell lines. Gynecol Oncol 94(3):760-768

26. Hussain SP, Harris CC (2007) Inflammation and cancer: An ancient link with novel potentials. Int $\mathrm{J}$ Cancer 121(11):2373-2380

27. Jemal A, Siegel R, Ward E, Hao Y, Xu J, Thun MJ (2009) Cancer statistics. CA: a Cancer J Clin 59(4):225-249 
28. Jeon YT, Song YS (2006) Cyclooxygenases in cancer: chemoprevention and sensitization to conventional therapies. Mini Rev Med Chem 6(7):827-833

29. Jobin C, Bradham CA, Russo MP, Juma B, Narula AS, Brenner DA, Sartor RB (1999) Curcumin blocks cytokine-mediated nf-kappa $\mathrm{b}$ activation and proinflammatory gene expression by inhibiting inhibitory factor i-kappa b kinase activity. J Immunol 163(6):3474-3483

30. Kasinski AL, Du Y, Thomas SL, Zhao J, Sun SY, Khuri FR, Wang CY, Shoji M, Sun A, Snyder JP, Liotta D, Fu H (2008) Inhibition of ikappab kinase-nuclear factor-kappab signaling pathway by 3 , 5-bis(2-flurobenzylidene)piperidin-4-one (ef24), a novel monoketone analog of curcumin. Mol Pharmacol 74(3):654-661

31. Kawamori T, Lubet R, Steele VE, Kelloff GJ, Kaskey RB, Rao CV, Reddy BS (1999) Chemopreventive effect of curcumin, a naturally occurring anti-inflammatory agent, during the promotion/progression stages of colon cancer. Cancer Res 59(3):597-601

32. Kunnumakkara AB, Anand P, Aggarwal BB (2008) Curcumin inhibits proliferation, invasion, angiogenesis and metastasis of different cancers through interaction with multiple cell signaling proteins. Cancer Lett 269(2):199-225

33. Landen CN Jr, Birrer MJ, Sood AK (2008) Early events in the pathogenesis of epithelial ovarian cancer. J Clin Oncol 26(6):995-1005

34. Lee MH, Choi BY, Kundu JK, Shin YK, Na HK, Surh YJ (2009) Resveratrol suppresses growth of human ovarian cancer cells in culture and in a murine xenograft model: Eukaryotic elongation factor $1 \mathrm{a} 2$ as a potential target. Cancer Res 69(18):7449-7458

35. Leiro J, Alvarez E, Arranz JA, Laguna R, Uriarte E, Orallo F (2004) Effects of cis-resveratrol on inflammatory murine macrophages: Antioxidant activity and down-regulation of inflammatory genes. J Leukoc Biol 75(6):1156-1165

36. Lin YG, Kunnumakkara AB, Nair A, Merritt WM, Han LY, Armaiz-Pena GN, Kamat AA, Spannuth WA, Gershenson DM, Lutgendorf SK, Aggarwal BB, Sood AK (2007) Curcumin inhibits tumor growth and angiogenesis in ovarian carcinoma by targeting the nuclear factor-kappab pathway. Clin Cancer Res 13(11):34233430

37. Luo H, Jiang BH, King SM, Chen YC (2008) Inhibition of cell growth and vegf expression in ovarian cancer cells by flavonoids. Nutr Cancer 60(6):800-809

38. Manna SK, Mukhopadhyay A, Aggarwal BB (2000) Resveratrol suppresses tnf-induced activation of nuclear transcription factors nf-kappa b, activator protein-1, and apoptosis: potential role of reactive oxygen intermediates and lipid peroxidation. J Immunol 164(12):6509-6519

39. McGettigan P, Henry D (2006) Cardiovascular risk and inhibition of cyclooxygenase: a systematic review of the observational studies of selective and nonselective inhibitors of cyclooxygenase 2. Jama 296(13):1633-1644

40. Mutoh M, Takahashi M, Fukuda K, Matsushima-Hibiya Y, Mutoh H, Sugimura T, Wakabayashi K (2000) Suppression of cyclooxygenase- 2 promoter-dependent transcriptional activity in colon cancer cells by chemopreventive agents with a resorcintype structure. Carcinogenesis 21(5):959-963

41. Myung SK, Ju W, Choi HJ, Kim SC (2009) Soy intake and risk of endocrine-related gynaecological cancer: A meta-analysis. Bjog 116(13):1697-1705

42. Ness RB, Cottreau C (1999) Possible role of ovarian epithelial inflammation in ovarian cancer. J Natl Cancer Inst 91(17):1459_ 1467

43. Nihal M, Ahmad N, Mukhtar H, Wood GS (2005) Anti-proliferative and proapoptotic effects of (-)-epigallocatechin-3-gallate on human melanoma: possible implications for the chemoprevention of melanoma. Int J Cancer 114(4):513-521
44. Ouyang G, Yao L, Ruan K, Song G, Mao Y, Bao S (2009) Genistein induces $\mathrm{g} 2 / \mathrm{m}$ cell cycle arrest and apoptosis of human ovarian cancer cells via activation of DNA damage checkpoint pathways. Cell Biol Int 33(12):1237-1244

45. Park SY, Jeong KJ, Lee J, Yoon DS, Choi WS, Kim YK, Han JW, Kim YM, Kim BK, Lee HY (2007) Hypoxia enhances lpa-induced hif-1alpha and vegf expression: their inhibition by resveratrol. Cancer Lett 258(1):63-69

46. Philip S, Kundu GC (2003) Osteopontin induces nuclear factor kappa b-mediated promatrix metalloproteinase-2 activation through i kappa $b$ alpha/ikk signaling pathways, and curcumin (diferulolylmethane) down-regulates these pathways. J Biol Chem 278(16): 14487-14497

47. Plummer SM, Holloway KA, Manson MM, Munks RJ, Kaptein A, Farrow S, Howells L (1999) Inhibition of cyclo-oxygenase 2 expression in colon cells by the chemopreventive agent curcumin involves inhibition of nf-kappab activation via the nik/ikk signalling complex. Oncogene 18(44):6013-6020

48. Rao CV, Rivenson A, Simi B, Reddy BS (1995) Chemoprevention of colon carcinogenesis by dietary curcumin, a naturally occurring plant phenolic compound. Cancer Res 55(2):259-266

49. Rao SD, Pagidas K (2010) Epigallocatechin-3-gallate, a natural polyphenol, inhibits cell proliferation and induces apoptosis in human ovarian cancer cells. Anticancer Res 30(7):2519-2523

50. Reuter S, Eifes S, Dicato M, Aggarwal BB, Diederich M (2008) Modulation of anti-apoptotic and survival pathways by curcumin as a strategy to induce apoptosis in cancer cells. Biochem Pharmacol 76(11):1340-1351

51. Rezk YA, Balulad SS, Keller RS, Bennett JA (2006) Use of resveratrol to improve the effectiveness of cisplatin and doxorubicin: Study in human gynecologic cancer cell lines and in rodent heart. Am J Obstet Gynecol 194(5):e23-e26

52. Schildkraut JM, Moorman PG, Halabi S, Calingaert B, Marks JR, Berchuck A (2006) Analgesic drug use and risk of ovarian cancer. Epidemiology 17(1):104-107 Cambridge, Mass

53. Schildkraut JM, Schwingl PJ, Bastos E, Evanoff A, Hughes C (1996) Epithelial ovarian cancer risk among women with polycystic ovary syndrome. Obstet Gynecol 88(4 Pt 1):554-559

54. Seo SS, Song YS, Kang DH, Park IA, Bang YJ, Kang SB, Lee HP (2004) Expression of cyclooxygenase-2 in association with clinicopathological prognostic factors and molecular markers in epithelial ovarian cancer. Gynecol Oncol 92(3):927-935

55. Shakibaei M, John T, Schulze-Tanzil G, Lehmann I, Mobasheri A (2007) Suppression of nf-kappab activation by curcumin leads to inhibition of expression of cyclo-oxygenase-2 and matrix metalloproteinase-9 in human articular chondrocytes: Implications for the treatment of osteoarthritis. Biochem Pharmacol 73(9):1434-1445

56. Sharma RA, Euden SA, Platton SL, Cooke DN, Shafayat A, Hewitt HR, Marczylo TH, Morgan B, Hemingway D, Plummer SM, Pirmohamed M, Gescher AJ, Steward WP (2004) Phase i clinical trial of oral curcumin: Biomarkers of systemic activity and compliance. Clin Cancer Res 10(20):6847-6854

57. Singh S, Aggarwal BB (1995) Activation of transcription factor nf-kappa b is suppressed by curcumin (diferuloylmethane) [corrected]. J Biol Chem 270(42):24995-25000

58. Siwak DR, Shishodia S, Aggarwal BB, Kurzrock R (2005) Curcumin-induced antiproliferative and proapoptotic effects in melanoma cells are associated with suppression of ikappab kinase and nuclear factor kappab activity and are independent of the b-raf/mitogen-activated/extracellular signal-regulated protein kinase pathway and the akt pathway. Cancer 104(4):879-890

59. Solomon LA, Ali S, Banerjee S, Munkarah AR, Morris RT, Sarkar FH (2008) Sensitization of ovarian cancer cells to cisplatin by genistein: The role of nf-kappab. J Ovarian Res 1(1):9 
60. Solomon SD, McMurray JJ, Pfeffer MA, Wittes J, Fowler R, Finn P, Anderson WF, Zauber A, Hawk E, Bertagnolli M (2005) Cardiovascular risk associated with celecoxib in a clinical trial for colorectal adenoma prevention. New Engl J Med 352(11): $1071-1080$

61. Subbaramaiah K, Michaluart P, Chung WJ, Tanabe T, Telang N, Dannenberg AJ (1999) Resveratrol inhibits cyclooxygenase-2 transcription in human mammary epithelial cells, vol 889. Annals of the New York Academy of Sciences, New York, pp 214-223

62. Surh YJ (2003) Cancer chemoprevention with dietary phytochemicals. Nat Rev 3(10):768-780

63. Tan X, Sidell N, Mancini A, Huang RP, Wang S, Horowitz IR, Liotta DC, Taylor RN, Wieser F (2010) Multiple anticancer activities of ef24, a novel curcumin analog, on human ovarian carcinoma cells. Reprod Sci 17(10):931-940

64. Thangapazham RL, Singh AK, Sharma A, Warren J, Gaddipati JP, Maheshwari RK (2007) Green tea polyphenols and its constituent epigallocatechin gallate inhibits proliferation of human breast cancer cells in vitro and in vivo. Cancer Lett 245(1-2):232-241

65. Tsai SH, Lin-Shiau SY, Lin JK (1999) Suppression of nitric oxide synthase and the down-regulation of the activation of nfkappab in macrophages by resveratrol. Bri J Pharmacol 126(3):673-680

66. Whittemore AS, Harris R, Itnyre J (1992) Characteristics relating to ovarian cancer risk: collaborative analysis of 12 us case-control studies. Ii. Invasive epithelial ovarian cancers in white women. Collaborative ovarian cancer group. Am J Epidemiol 136(10):1184-1203

67. Zhang F, Altorki NK, Mestre JR, Subbaramaiah K, Dannenberg AJ (1999) Curcumin inhibits cyclooxygenase-2 transcription in bile acid- and phorbol ester-treated human gastrointestinal epithelial cells. Carcinogenesis 20(3):445-451

68. Zhang M, Xie X, Lee AH, Binns CW (2004) Soy and isoflavone intake are associated with reduced risk of ovarian cancer in southeast china. Nutrit Cancer 49(2):125-130 